\title{
Sero-Prevalence of Syphilis among Pregnant Women Attending Antenatal Careclinic at Jimma Univeristy Specialized Hospital, Ethiopia
}

\author{
Bisrat Fikadu ${ }^{1}$, Sisay Gebrish ${ }^{1}$, Tsegahun Asfaw ${ }^{2 *}$ \\ ${ }^{I}$ Department of Medical Laboratory Science, Debre Berhan Health Science College, Debre Berhan, Ethiopia \\ ${ }^{2}$ Department of Medical Laboratory Science, Debre Berhan University, Debre Berhan, Ethiopia
}

*Corresponding Author: Tsegahun Asfaw, Department of Medical Laboratory Science, Debre Berhan

University, Debre Berhan, Ethiopia.

\begin{abstract}
Background: Syphilis is a disease caused by bacteria called Treponema pallidum. It is transmitted through sexual contact, blood transfusion and via vertically from mother to fetus in utero. Untreated syphilis during pregnancy can greatly affect pregnancy outcome, resulting in spontaneous abortion, and stillbirth.The aim of the study was to determine the sero-prevalence of syphilis among pregnant women attending for Antenatal Care $(A N C)$ service.
\end{abstract}

Methods: A cross-sectional study was conducted from January to June, 2016 at Jimma University specialized hospital, Southwest Ethiopia. A total 181 study subject were recruited by conveniently. Socio demographic and clinical data was collected by pre-tested structured questioners. Two milliliter of blood was collected to determined sero-prevalence of syphilis using Florescent Treponema antibody Absorption (FTA-Abs) test. The data was analyzed by using SPSS version 21. The association between independent and dependent variables was determined. P-value less than 0.05 was considered as statistically significant value.

Result: Among a total of 181 participants, only 2/181 (1.1\%) women were seropositive for syphilis. Among participants, $41.4 \%$ of them were found in age group of 21-25 years, $77.9 \%$ of them were married while $3.9 \%$ were widowed. $66.3 \%$ of them were from urban area. Residence and sexual status of syphilis showed significant association.

Conclusion: Syphilis seropositive cases were observed among married women who come from rural area with age group of 26-35 years. Therefore, health education on etiology, prevention and control of syphilis has to be provided for the community.

Keywords: Sero-Prevalence, Syphilis, Pregnant Mothers

\section{INTRODUCTION}

Syphilis is a systemic disease caused by Triponema palladium which can be spread by sexual contact, blood transfusion and via vertically from mother to fetus in utero. The World Health Organization estimates 10-12 million new infections of syphilis occur every year. And also, Infection rates show extreme variation between countries of the same region as well as various subcategories of populations studied (1). If not treated, syphilis can cause serious problems such as damage to the aorta, brain, eyes, and bones. In some cases it may be resulted in fatal. Testing for syphilis during pregnancy and labor is medically important because, syphilis infection has a potential risk for congenital infection and fetal loss (2).

Syphilis has also a new potential for morbidity and mortality through association with increased risk for HIV infection (3). Pregnant women should have serologic test for syphilis at the time of the first prenatal visit. In women suspected of being at increased risk for syphilis or for populations in which there is a high prevalence of syphilis, additional tests should be performed during the third trimester at twenty-eight weeks and again at delivery. Seropositive women should be considered infected and should be treated unless prior treatment with fall in antibody titer is medically documented (4).

The mother can transmit the infection transplacentally to the fetus or during passage through the birth canal by contact of the newborn with a genital lesion. Breast feeding does not result in the transmission of syphilis, unless an infectious lesion is present on the breast. Until recently, a 
commonly held but erroneous obstetric principle stated that infection of the fetus does not occur before 18 weeks. Silver and immunofluorescence staining of the fetal tissue, or polymerase chain reaction and rabbit infectivity testing of amniotic fluid showed that $T$. pallidumgains access to the fetal compartment as early as $9-10$ weeks. (5)

Untreated syphilis during pregnancy can affect pregnancy outcome, resulting in spontaneous abortion, stillbirth, non-immune hydrops-fetalis, intrauterine growth restriction, premature delivery and perinatal death, as well as serious sequel in live born infected children $(5,6)$.Appropriate treatment of pregnant women often prevents such complication. Screening in the first trimester with VDRL and RPR test combine with confirmation of reactive individuals with Treponema tests such as fluorescent Treponema antibody absorption (FTA-Abs) assay is a cost effective strategies.

\section{MeTHOdS AND MATERIALS}

\subsection{Study Area}

The study was conducted at Jimma university specialized hospital, Jimma town, south west Ethiopia. It is located $352 \mathrm{~km}$ southwest of Addis Ababa .It provides specialized health services for approximately 9000 inpatients and 80000 outpatients each year with bed capacity of 450 and a total of more than 550 staff. According to the national 2015 census, this town had a total population of 120,960 of whom 60,824 were men and 60136 were women.

\subsection{Study Design and Period}

Cross sectional study was conducted from January to June, 2016.

\subsection{Sample Size and Sampling Technique}

A total of 181 pregnant women were conveniently selected for this study.

\subsection{Data Collection Procedures}

The socio-demographic characteristics of all pregnant women coming to antenatal care clinic was taken by using pre-tested structured questionnaire. The clinical data was taken by physician from all study participants. Two milliliter of blood was collected for Florescent Treponema antibody Absorption (FTA-Abs) test. The test was done for all 181 pregnant women in their first trimester pregnancy periods.

\subsection{Data Processing and Analysis}

The collected data was clearly summarized, filled and analyzed by using SPSS version 21. Descriptive statistics was employed and the result was presented by using tables. The association between independent and dependent variables was determined. P-value less than 0.05 was considered as statistically significant value.

\subsection{Quality Assurance}

The data was collected by trained data collectors and the result was recorded carefully and correctly. Standard operating procedure for the laboratory procedures (using Florescent Treponema antibody Absorption test (FTA-Abs) test) was strictly followed.

\subsection{Ethical Consideration}

Ethical approval was obtained from Research and Review Committee of Jimma University. Official permission was obtained from head department of Jimma university specialized hospital. For all study participant the objective of the study was explained and written informed consent was obtained. Those pregnant mother positive for syphilis was referred to their respective clinicians for further management.

\section{RESUlT}

Among a total of 181participants, only 2/181 (1.1\%) women were sero positive for syphilis. From a total participant, $41.4 \%$ of them were found in age group of $21-25$ years old. $77.9 \%$ of them were married while $3.9 \%$ were widowed. $66.3 \%$ of them were from urban while other $37.3 \%$ were from rural area. $32.6 \%$ of them had monthly income of 900-1200 Ethiopian birr while 5.5\% had monthly income of $<300$ Ethiopian birr. $40.9 \%$ of them were house wife while $8.8 \%$ were student. $93.9 \%$ has no multiple sexual partner while others $6.1 \%$ had multiple sexual partner. $29.8 \%$ of them were can read and write. While $9.9 \%$ were illiterate. The age, marital status, monthly income, occupation and educational status of the participant showed no significant association while residence and sexual status of syphilis showed significant association. 
Sero-Prevalence of Syphilis among Pregnant Women Attending Antenatal Careclinic at Jimma Univeristy Specialized Hospital, Ethiopia

Table1. Socio-demographic Characteristics of Pregnant Women Attending Antenatal Care Clinic at Jimma University Specialized Hospital from January-June, 2016.

\begin{tabular}{|c|c|c|c|c|c|c|c|c|}
\hline \multicolumn{2}{|l|}{ Variables } & \multicolumn{6}{|c|}{ RPR result } & \multirow[t]{3}{*}{ P-value } \\
\hline & & \multicolumn{2}{|c|}{ Positive } & \multicolumn{2}{|c|}{ Negative } & \multicolumn{2}{|c|}{ Total } & \\
\hline & & № & $\%$ & № & $\%$ & № & $\%$ & \\
\hline \multirow[t]{5}{*}{ Age } & $15-20$ & 0 & 0 & 22 & 12.2 & 22 & 12.2 & \multirow[t]{5}{*}{0.364} \\
\hline & $21-25$ & 0 & 0 & 75 & 41.4 & 75 & 41.4 & \\
\hline & $26-30$ & 1 & 0.55 & 59 & 32.6 & 60 & 33.1 & \\
\hline & $31-35$ & 1 & 0.55 & 18 & 9.9 & 19 & 10.5 & \\
\hline & $>36$ & 0 & 0 & 5 & 2.8 & 5 & 2.8 & \\
\hline \multirow{4}{*}{$\begin{array}{l}\text { Marital } \\
\text { status }\end{array}$} & Single & 0 & 0 & 11 & 6.1 & 11 & 6.1 & \multirow[t]{4}{*}{0.902} \\
\hline & Married & 2 & 1.1 & 139 & 76.8 & 141 & 77.9 & \\
\hline & Widowed & 0 & 0 & 7 & 3.9 & 7 & 3.9 & \\
\hline & Divorced & 0 & 0 & 22 & 12.2 & 22 & 12.2 & \\
\hline \multirow[t]{2}{*}{ Residence } & Urban & 0 & 0 & 120 & 66.3 & 120 & 66.3 & \multirow[t]{2}{*}{0.046} \\
\hline & Rural & 2 & 1.1 & 59 & 32.6 & 61 & 33.7 & \\
\hline \multirow{5}{*}{$\begin{array}{l}\text { Monthly } \\
\text { income }\end{array}$} & $<300$ & 0 & 0 & 10 & 5.5 & 10 & 5.5 & \multirow[t]{5}{*}{0.129} \\
\hline & $300-600$ & 0 & 0 & 32 & 17.7 & 32 & 17.7 & \\
\hline & $600-900$ & 2 & 1.1 & 38 & 21.0 & 40 & 22.1 & \\
\hline & $900-1200$ & 0 & 0 & 59 & 32.6 & 59 & 32.6 & \\
\hline & $>1200$ & 0 & 0 & 40 & 22.1 & 40 & 22.1 & \\
\hline \multirow[t]{4}{*}{ Occupation } & House wife & 2 & 1.1 & 72 & 39.8 & 74 & 40.9 & \multirow[t]{4}{*}{0.403} \\
\hline & Government employee & 0 & 0 & 37 & 20.4 & 37 & 20.4 & \\
\hline & Student & 0 & 0 & 16 & 8.8 & 16 & 8.8 & \\
\hline & Merchant & 0 & 0 & 54 & 29.8 & 54 & 29.8 & \\
\hline \multirow{5}{*}{$\begin{array}{l}\text { Educational } \\
\text { status }\end{array}$} & Illiterate & 1 & 0.55 & 17 & 9.4 & 18 & 9.9 & \multirow[t]{5}{*}{0.310} \\
\hline & Can read and write & 1 & 0.55 & 53 & 29.3 & 54 & 29.8 & \\
\hline & Grade 1-6 & 0 & 0 & 45 & 24.9 & 45 & 24.9 & \\
\hline & grade $7-12$ & 0 & 0 & 42 & 23.2 & 42 & 23.2 & \\
\hline & Grade $>12$ & 0 & 0 & 22 & 12.2 & 22 & 12.2 & \\
\hline \multirow{3}{*}{$\begin{array}{l}\text { Sexual } \\
\text { partner }\end{array}$} & Yes & 2 & 1.1 & 9 & 5.0 & 11 & 6.1 & \multirow[t]{2}{*}{0.00001} \\
\hline & No & 0 & 0 & 170 & 93.9 & 170 & 93.9 & \\
\hline & Total & 2 & 1.1 & 179 & 98.9 & 181 & 100 & \\
\hline
\end{tabular}

\section{DISCUSSION}

Syphilis remains a major cause of morbidity and mortality in the world despite the availability of effective treatment. Interventions including early antenatal care, massive screening and prompt treatment with antibiotics.

In this study from a total of 181 pregnant women only $2(1.1 \%)$ of them were sero-positive for syphilis. Those are in the age group of 25-35 years. It is almost similar to study done in Debre Berhan Ethiopia1.8\% (3) but lower than study done in Gondar, Ethiopia, 2.9\% (7). It is also much smaller from study done in Labor Ward at Wolaita Sodo University Teaching Referral Hospital 3.7\% (8) and in rural hospital of Northwest Ethiopia13.7\%(9).This study also showed smaller sero-prevalence of syphilis among pregnant mother from study in Kahartoum State Sudan 3\% (10). Despite sample size difference, it is similar to a study done in Pakistan at Karachi hospital which showed among 100,000 women attending ANC, 875 women were seropositive for syphilis. The prevalence of syphilis in this study was $875(0.9 \%)$ where seropositive case was found in age group greater than 25 years old (11).A comparable result was also obtained from research done in Brazil; where syphilis prevalence in pregnancy was $1.02 \%$ (12). However, slightly higher in antenatal clinic in southern Nigerian $2.2 \%(13)$. This difference might be due to sample size and type of test.

An increased prevalence of syphilis was observed among women with low or no education. And also the 2 seropositive participants were married. This is totally different from study done in Brazil(12). This might be the difference in health education and awareness creation among study participants in the two country.

The present study showed that $93.9 \%$ were not having multiple sexual partner and $6.1 \%$ were have multiple sexual partner. $2(1.1 \%)$ were positive for syphilis and had multiple sexual partner. The prevalence of syphilis in individuals having multiple sexual partners is still higher and there is a significant association. This result was lower than the finding obtained from Nigeria (13). This may be due to the difference in sample size and participant's knowledge or awareness on etiology, prevention and control of syphilis 
Sero-Prevalence of Syphilis among Pregnant Women Attending Antenatal Careclinic at Jimma Univeristy Specialized Hospital, Ethiopia

\section{CONCLUSION AND RECOMMENDATION}

Syphilis seropositive cases were observed among married women and those who come from rural area in the age group of 26-35 years. These indicate that there is still the problem of syphilis in the present study area. Thus, it is essential to strengthen the existing ANC services and health education on transmission and prevention of this disease. It is advisable for pregnant women to be screened for syphilis it will help to eliminate the adverse effects of untreated Syphilis.

FUNDING

This work was funded from Jimma University core budget.

\section{AUTHORS' CONTRIBUTIONS}

BF-performed the laboratory activities. BF, SG and TA- analyzed the data. TA-wrote the manuscript. All authors read and approved the final manuscript.

\section{ACKNOWLEDGMENT}

We would like to thank Jimma for giving this opportunity and availing the resources. We also thank staffs and head of Jimma university specialized hospital for their help during data collection process.

\section{REFERENCES}

[1] World Health Organization Department of HIV/ADIS .Global prevalence and incidence of selected curable sexually transmitted disease: overview estimate. Geneva WHO2001

[2] Safe Motherhood Practical Guide. Division of Family Health WHO Geneva WHO/MCH 2004, 91.10.

[3] Seblewongale Zinabie, Emishaw Belachew, Teferi Yidenek, Moges Lewetegn, Tsegahun Asfaw, SeroPrevalence of Syphilis and HIV and Associated Factors in Pregnant Women Attending Antenatal Care Clinics in Debre Berhan Public Health Institutions, Ethiopia, American Journal of Biomedical and Life Sciences. 2018,Vol. 6, No. 3, pp. 56-62.

[4] Haroon SA; Sithembiso VE; Yasmin GO; Nike AF; Richard ST; Ornella LI, The prevention and management of congenital syphilis: an overview and recommendations Bull World Health Organ2004: vol.82 n.6.

[5] Azeze B., Fantahun M., Kidan K.G. and Haile T. Seroprevalenceof Syphilis amongst pregnant women attending antenatal clinics in a rural hospital in North-West Ethiopia. Genitourinary. Med. 1995; 71:3.

[6] Sadia KH, MD, Clinical Assistant Professor Seroprevalence of syphilis in patients attending a tertiary care hospital in Southern India Asian. Pac J Trop Biomed. 2014; 4(12): 995-997.

[7] Amsalu A, Ferede G, Assegu D. High seroprevalence of syphilis infection among pregnant women in Yiregalem hospital southern Ethiopia. BMC Infect Dis. 2018; 18 (1):109.

[8] Temesgen Anjulo Ageru, Temesgen Lera Abiso, Sero-Prevalence of HIV and Syphilis Infection Among Pregnant Mothers Attended Labor Ward at Wolaita Sodo University Teaching Referral Hospital:A FiveYear Retrospective Study (2012-2016), American Journal of Health Research. 2018, Vol. 6, No. 3, pp. 6773.

[9] Azeze B, Fantahun M, Kidan KG, Haile T. Seroprevalence of syphilis amongst pregnant women attending antenatal clinics in a rural hospital in north west Ethiopia. Genitourin Med. 1995; 71(6):347-50.

[10] Abdelmola AO. Prevalence and factors associated with syphilis among pregnant women attending antenatal care, Khartoum State, Sudan. International journal of advance in Medicine 2018, Vol 5, No 2.

[11] Shah SA, Kristensen S, Memon MA, Usman G, Ghazi A, John R, Sathiakumar N, Vermund SH. Prevalence of syphilis among antenatal clinic attendees in Karachi: Imperative to begin universal screening in Pakistan.J Pak Med Assoc. 2011 October; 61(10): 993-997.

[12] Rosa MSMD, Celia LS, PauloRoberto BSJ, Maria dL. Prevalence of syphilis in pregnancy and prenatal syphilis testing in Brazil: Birth in Brazil study.Rev Saude Publica. 2014:48:5.

[13] wuezobe IA , Ochang EA, Umoiyoho A , Bassey EA , Muffia EM Prevalence of syphilis seropositivity in antenatal clinic clients in a teaching hospital in South-South region of Nigeria.Asian Pacific Journal of Tropical Disease. 2011; 21-23

Citation: Tsegahun Asfaw et.al." Sero-Prevalence of Syphilis among Pregnant Women Attending Antenatal Careclinic at Jimma Univeristy Specialized Hospital, Ethiopia", International Journal of Research Studies in Microbiology and Biotechnology (IJRSMB), vol. 5, no. 1, pp. 28-31, 2019. Available: DOI: http://dx.doi. org/10.20431/2454-9428.0501004

Copyright: () 2019 Authors. This is an open-access article distributed under the terms of the Creative Commons Attribution License, which permits unrestricted use, distribution, and reproduction in any medium, provided the original author and source are credited. 